surgery. When operation is imperative, splenorrhaphy, partial splenectomy, or heterotopic autotransplantation should be considered. ${ }^{17}$ Autotransplantation may lead to the return of functioning splenic tissue and provide some protection against subsequent overwhelming infection. ${ }^{18}$ Animal studies have shown, however, that the immune function of autotransplanted tissue is inferior to that of normal splenic tissue. ${ }^{19}$ Vaccination and prophylaxis with antibiotics are still required after autotransplantation.

The absence of a spleen leads to impaired resistance to bloodborne protozoal infection. Malaria and babesiosis (infections transmitted by ticks) have a high mortality in people without spleens. ${ }^{20}$ Such people should therefore avoid areas where malaria is endemic and those who work with animals should be aware of the dangers of tick bites.

MARY MCMULLIN

Queen's University of Belfast,

Senior lecturer in haematology

Belfast BT12 6BL

GEORGE JOHNSTON

Consultant surgeon

Royal Victoria Hospital,

Belfast BT12 6BA
1 Singer DB. Postsplenectomy sepsis. In: Rosenberg HS, Bolande RP, eds. Perspectives in pediatric pathology. Chicago: Year Book Medical Publishers, 1973:285-311.

Holdsworth RJ, Irving AD, Cuschieri A. Postsplenectomy sepsis and its mortality rate: actual versus perceived risks. Br f Surg 1991;78:1031-8.

3 Pimpl W, Dapunt $\mathrm{O}$, Kaindl $\mathrm{H}$, Thalhamer J. Incidence of septic and thromboembolic-related deaths after splenectomy in adults. Br $\mathcal{F}$ Surg 1989;76:517-21.

Dickerman JD. Traumatic asplenia in adults. A defined hazard? Arch Surg 1981;116:361-3.

4 Dickerman JD. Traumatic asplenia in adults. A defined hazard? Arch Surg 1981;116.35

6 Zarrabi MH, Rosner F. Serious infections in adults following splenectomy for trauma. Arch Intern Med 1984;144:1421-4.

7 Deodhar HA, Marshall RJ, Barnes JN. Increased risk of sepsis after splenectomy. BMf 1993;307:1408-9.

8 Ellison EC, Fabri PJ. Complications of splenectomy: etiology, prevention and management. Surg Clin North Am 1983;63:1313-30.

9 Shapiro ED, Berg AT, Austrian R, Schroeder D, Parcells V, Margolis A, et al. The protective efficacy of polyvalent pneumococcal polysaccharide vaccine. $N$ Engl F Med 1991;325:1453-60.

10 DiPadova F, Durig $M$, Wadstrom J, Harder $F$. Role of the spleen in response to polyvalent pneumococcal vaccine. $B M \mathcal{Y} 1983 ; 287: 1829-32$.

11 Department of Health. Immunisation against infectious disease. London: HMSO, 1992:100-3.

12 Kinnersley $P, W$ ilkinson $C E$, Srinivasan J. Pneumococcal vaccination after splenectomy: survey of hospital and primary care records. BMf 1993;307:1398-9.

13 Zarrabi MH, Rosner F. Rarity of failure of penicillin prophylaxis to prevent postsplenectomy sepsis. Arch Intern Med 1986;146:1207-8.

14 Evans DIK. Fatal postsplenectomy sepsis despite prophylaxis with penicillin and pneumococcal vaccine. Lancet 1984;i:1124.

15 Brivit F, Herer B, Fremaux A, Dormont J, Tchernia G. Fatal postsplenectomy sepsis despite pneumococcal vaccine and penicillin prophylaxis. Lancet 1984 ;ii:356-7.

16 Teare $\mathrm{L}$, O'Riordan S. Is splenectomy another indication for Haemophilus influenzae type b vaccination? Lancet 1992;340:1362.

17 Shaw JHF, Print CG. Postsplenectomy sepsis. Br f Surg 1989;76:1074-81.

18 Nicholson S, Hutchinson GH, Hawkins T, Venables CW. Successful splenosis following autologous splenic implantation. $\mathcal{F} R$ Coll Surg Edinb 1986;31:67-71.

19 Cooney DR, Dearth JC, Swanson SE, Dewanjee MR, Telander RL. Relative merits of partial splenectomy, splenic reimplantation and immunization in preventing postsplenectomy infection. Surgery 1979;86:561-8.

20 Shute PG. Splenectomy and susceptibility to malaria and babesia infection. $B M \mathcal{F} 1975 ; \mathrm{i}: 516$.

\title{
Alcohol and heart disease: the implications of the U-shaped curve,/
}

\section{The recommended weekly limits of 21 units (men) and 14 units (women) should be adhered to}

Numerous studies have shown that people who drink small amounts of alcohol experience lower rates of ischaemic heart disease than those who do not drink alcohol. ${ }^{1}$ These studies show consistency, specificity, and a dose-response effect, thereby fulfilling the criteria for believing an association to be causal. ${ }^{2}$ Furthermore, a protective effect of alcohol against heart disease is biologically plausible. A few authorities still argue that the epidemiological evidence can be explained without causality being invoked, ${ }^{3}$ but most concede that small amounts of alcohol may be cardioprotective. ${ }^{4}$ Ischaemic heart disease is common, and in most studies the relative risks for moderate drinkers compared with abstainers are of the order of $0 \cdot 5-0 \cdot 7$, so the effect could be more than trivial.

In Britain it has been accepted that there is no harm in consuming small amounts of alcohol. Drinking that results in intoxication, a high intake long term, or dependence, however, causes considerable harm. The harm includes various physical and psychological illnesses and a broad range of social problems. Heavy drinkers are heavy users of hospital inpatient services, accident and emergency departments, and general practice. ${ }^{5}$

Advice to individual members of the public has been fairly consistent over the past decade. Men should keep their alcohol consumption below 21 units a week and women below 14 units a week (a half pint of beer, a glass of wine, and a single measure of spirits each contains about a unit of alcohol). Everyone accepts that these limits are arbitrary, that people differ in their susceptibility to harm from alcohol, and that there is a continuum of risk with increasing intake. None the less, patients advised to cut down on their drinking may reasonably ask, "Well, how much can I drink, doctor?" and a rough and ready guide is much better than no answer.

Although unreliable estimates of alcohol intake and varying groupings of levels of consumption make comparison between studies difficult, ${ }^{6}$ some broad conclusions are possible. In most studies men who drink about 7 units a week have rates of heart disease that are close to the lowest. The curve is flat bottomed, and men who drink considerably more do not have higher rates of heart disease until they drink over 40 units a week. For other causes of death, such as accidents, stroke, and liver disease, the rates start to rise at lower intakes. In studies recording all cause mortality the lowest rates coincided with an alcohol consumption of about 7 units a week, with higher rates in those drinking more than 21 units a week. The longstanding recommended limit for men of 21 units a week fits surprisingly well with these data. For women we need more data, but the 14 unit a week limit will probably prove reasonable.

Public health doctors have advised that the whole population should reduce its mean consumption. ${ }^{7}$ Public policy on alcohol must consider not only mortality and rates of medically defined non-fatal disease but also alcohol's harmful effects on family and social life, public order and criminality, and productivity at work. These probably have more impact on people's health than any "medical" effects of alcohol. The data are insufficient to allow a quantitative discussion of the relation between different levels of individual consumption and this non-medical harm, but harm certainly occurs at fairly low levels of consumption. ${ }^{8}$ Ignoring the likely effect of any change in advice on drinking on these types of harm would be rash.

Any effect of alcohol on rates of ischaemic heart disease in England and Wales has been swamped by other factors. Between 1940 and 1980, when deaths from ischaemic heart disease were rising most rapidly, alcohol consumption also rose sharply; the fall in heart disease in the past decade has coincided with a period of fairly stable alcohol consumption.

Any general encouragement to drink alcohol will predictably increase the number of heavy drinkers: the mean consumption of alcohol correlates closely with the prevalence of heavy drinking in population groups. ${ }^{\text {The }}$ Thalance of evidence still suggests that Britain would be healthier if we could shift the curve of alcohol consumption to the left. For men to limit their alcohol consumption to below 21 units a 
week and for women to limit theirs to below 14 units still looks a good rule of thumb.

Department of Public Health and Epidemiology, JOHN/KEMM Senior lecturer

The Medical School,

Birmingham B15 2TT

1 Renaud S, Criqui MH, Frachi G, Veenstra J. Alcohol drinking and coronary heart disease. In Vershuren PM, ed. Health issues related to alcohol consumption. Washington: ILSI Press, 1993:4.
Marmot MG. Alcohol consumption and coronary heart disease. Int $\mathcal{Y}$ Epidemiol 1984;13:160-7 3 Shaper AG. Alcohol and mortality: a review of prospective studies. $\operatorname{Br}$ f Addict 1990;85: 837-47.

Me. Good news that complicates at Faculty of Public Health Medicine. 1991.

6 Tumer $C$. How much alcohl is a standad dinte An antys of 125 sudies. Br f Addict 1990;84:1171-5.

7 Faculty of Community Medicine. Health for all by the year 2000: charter for action. London: FCM 1986.

8 Krietman N. Alcohol consumption and the preventive paradox. Br $f$ Addict 1986;81:353-63.

9 Rose G, Day S. The population mean predicts the number of deviant individuals. $B M \mathcal{J}$ 1990;301:1031-4.

\title{
Brief interventions for alcohol misuse
}

\author{
Effective, but not for all alcohol misusers
}

Despite a plateau in per capita alcohol sales in Britain in the past decade ${ }^{1}$ the rise in deaths from cirrhosis of the liver has continued. ${ }^{2}$ Scottish research also found a rise in discharges from general hospitals for all alcohol related disorders. ${ }^{3}$ In part, but only in part, this may reflect doctors' growing readiness to record alcohol problems in medical and surgical patients: in urban hospitals in Britain 15-30\% of men and 8$15 \%$ of women have alcohol problems. ${ }^{4}$ The value of this recognition is that when a doctor or nurse talks to patients about their consumption of alcohol and its pros and cons, providing information non-judgmentally, some patients reduce their drinking and problems from drinking fall.

Control patients in studies showing this effect have been excessive drinkers who received no counselling (other than might have occurred in routine medical practice). Controlled studies of brief interventions in over 4000 patients in medical settings have now been published. Some have presented data not only on self reported consumption but also on objective markers of outcome, such as a fall in serum $\gamma$ glutamyltransferase activity over the ensuing year ${ }^{5}$ or a fall in recorded days of sickness and admissions to hospitals. ${ }^{67}$

The most recent issue of Effective Health Care has examined randomised studies that used assessors who were meant to be blind to the treatment group and that included measures of self reported consumption of alcohol. Data from the six studies meeting these criteria were pooled: overall, the effect of brief intervention was estimated to be a $24 \%$ fall in alcohol consumption (95\% confidence interval $18 \%$ to $31 \%) .{ }^{8}$ In a metaanalysis published earlier this year of 19 brief intervention studies in non-medical settings, using data with slightly varying measures of alcohol consumption, the mean treatment effect was $38 \%$ (range $-3 \%$ to $64 \%$; SD $33 \%$ ). ${ }^{9}$

The estimated direct cost of detection and brief intervention in an alcohol misuser to reduce alcohol consumption by an average of one quarter is $£ 20 .^{7}$ Decision makers in the health service may be impressed and may question the need for more costly services for problem drinkers.

The decision makers should, however, note two points. Firstly, most of the studies included in these reviews of brief intervention excluded severely affected drinkers who were thought to need psychiatric referral, had symptoms of physical dependence, or who lacked social support. Secondly, although brief intervention may increase the proportion of alcohol misusers who get through a year without drinking dangerous amounts or without problems, large numbers of misusers continue to drink as much or more and develop problems. They need other treatments.

The authors of the study in Effective Health Care rightly conclude that for more severely affected drinkers there is no certainty about what constitutes the most effective treatment. The advantages of inpatient versus outpatient care, other than perhaps for detoxifying socially unsupported patients and for those at risks of delirium or fits, have been difficult to show. ${ }^{10}$

The value of brief intervention in less severely affected misusers seems not in doubt. Although severely affected drinkers have the highest rates of alcohol problems, less severely affected misusers are more numerous and contribute more to alcohol's health and social costs. The main ingredients in the opportunistic counselling of such patients have been dubbed FRAMES ${ }^{9}$ : Feedback to the patient about personal risk or impairment; emphasis on personal Responsibility for change; Advice; a Menu of alternative options for change; and interviewing which is Empathic and enhances Self efficacy. Health workers should recognise that patients will be at different stages in their thinking about alcohol. Some are already thinking of change. Others are not and resist advice: opening the dialogue may be all that is appropriate then. ${ }^{11}$

Effective Health Care advises on ways of identifying alcohol misusers. Screening instruments have been devised (for example, the alcohol use disorders identification test (AUDIT $)^{12}$ ), but incorporating into routine medical practice a question on the quantity and frequency of units consumed and whether drinking has led to any problems detects many cases of alcohol misuse, and the question can be repeated later if there is an unexplained rise in $\gamma$ glutamyltransferase activity or mean red cell volume.

Purchasers should note that the awareness among doctors and nurses of alcohol misuse still needs to be increased. They will also find that, in general hospitals and primary care, nurses who are good at helping patients change their behaviour can be productively employed.

Royal Edinburgh Hospital,

JONATHAN CHICK Consultant psychiatrist Edinburgh EH10 5HF

\footnotetext{
1 Brewers' Society. Brewers' Society statistical handbook. London: Brewing Publications, 1992. 2 Office of Population Censuses and Surveys. Mortality statistics. Review of the registrar general on deaths by cause, sex, and age in England and Wales 1968-91. London: HMSO, 1993 (DH2 series.) Findlay A. Alcohol misuse in Scotland-is there a growing health problem? Health Bulletin 1991;49:273-83.

4 Chick J. Alcohol problems in the general hospital. BrMed Bull (in press).

5 Nilssen $O$. The Tromso study: identification of and a controlled intervention on a population of early-stage risk drinkers. Prev Med 1991;20:518-28.

6 Kristenson H, Ohlin H, Hulter-Nosslin M, Troll E, Hood B. Identification of heavy drinking in

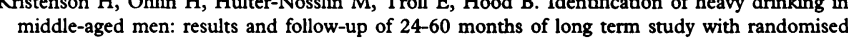
middle-aged men: results and follow-up of 24

7 Persson J, Magnusson P-H. Early intervention in patients with excessive consumption of alcohola controlled study. Alcohol 1989;6:103-8.

8 Freemantle N, Gill P, Godfrey C, Long A, Richards C, Sheldon T, Song F, et al. Brief interventions and alcohol use-are brief interventions effective in reducing harm associated with alcohol consumption? Effective Health Care 1993; No 7.

9 Bien TH, Miller WR, Tonigan JS. Brief interventions for alcohol problems: a review. Addiction 1993;88:315-36.

10 Chick J. Emergent treatment concepts. In: Langenbucher JW, Nathan P, McCrady BS, Frankenstein W, eds. Annual Review of addiction research and treatment. New York: Pergamon, 1992:297-312.

11 Rollnick S, Kinnersley P, Stott N. Methods of helping patients with behaviour change. $B M \mathcal{F}$ 1993;307:188-90.

12 Saunders J, Aasland OG, Babor TF, De La Fuente JR, Grant M, et al. Development of the alcohol use disorders identification test (AUDIT): WHO collaborative project on early detection of persons with harmful alcohol consumption-II. Addiction 1993;88:791-804.
} 